\title{
Perceived discrimination and health outcomes among middle-aged and older adults in India: results of a national survey in 2017-2018
}

Supa Pengpid ${ }^{1,2}$ and Karl Peltzer ${ }^{2,3^{*}}$

\begin{abstract}
Background: The study aimed to estimate the associations between perceived discrimination and poor physical health, poor mental health, and health risk behaviours in middle-aged and older adults in a national population survey in India.

Methods: The sample included 72,262 middle-aged and older adults from a cross-sectional national community dwelling survey in India in 2017-2018.

Results: The prevalence of moderate (1-2 types) perceived discrimination was 10.7\%, and high (3-6 types) perceived discrimination was $6.6 \%$. In the final adjusted logistic, linear or Poisson regression analyses, moderate and/or high perceived discrimination was significantly positively associated with poor mental health (low life satisfaction, poor cognitive functioning, insomnia symptoms, and depressive symptoms), poor physical health (pain conditions count, and functional limitations), and health risk behaviours (heavy episodic drinking and physical inactivity).

Conclusion: Perceived discrimination is associated with poor mental health, poor physical health, and health risk behaviour, emphasising the need to consider perceived discrimination in various physical and mental health contexts.
\end{abstract}

Keywords: Perceived discrimination, Physical health, Mental health, Health risk behaviour middle-aged, Older adults, India

\section{Background}

Perceived discrimination can be defined as "a behavioural manifestation of a negative attitude, judgment, or unfair treatment toward members of a group", such as age, gender, race and ethnicity, religion, caste, weight, physical disability, physical appearance, and financial

\footnotetext{
* Correspondence: kfpeltzer@gmail.com

${ }^{2}$ Department of Research Administration and Development, University of Limpopo, Turfloop, Polokwane, South Africa

${ }^{3}$ Department of Psychology, College of Medical and Health Science, Asia University, Taichung, Taiwan

Full list of author information is available at the end of the article
}

status, and can be characterised as a form of stress [1]. There are two different types of perceived discrimination, one is referring to major lifetime experiences including singular incidents in society such as the housing or labour market, and the second type is everyday perceived discrimination including daily interpersonal hassles and insults encompassing chronic psychosocial stressors [2]. There are several pathways on how perceived discrimination affects health [3]. Following ecosocial theory "lived realities of.

C C The Author(s). 2021 Open Access This article is licensed under a Creative Commons Attribution 4.0 International License, which permits use, sharing, adaptation, distribution and reproduction in any medium or format, as long as you give appropriate credit to the original author(s) and the source, provide a link to the Creative Commons licence, and indicate if changes were made. The images or other third party material in this article are included in the article's Creative Commons licence, unless indicated otherwise in a credit line to the material. If material is not included in the article's Creative Commons licence and your intended use is not permitted by statutory regulation or exceeds the permitted use, you will need to obtain permission directly from the copyright holder. To view a copy of this licence, visit http://creativecommons.org/licenses/by/4.0/ The Creative Commons Public Domain Dedication waiver (http://creativecommons.org/publicdomain/zero/1.0/) applies to the data made available in this article, unless otherwise stated in a credit line to the data. 
discrimination as an exploitative and oppressive societal phenomenon operating.

at multiple levels and involving myriad pathways across both the life course and historical.

generations" need to be considered [4]. Routine discrimination may become a chronic stressor weaking a person's protective and self-control resources and thereby increasing one's vulnerability to detrimental mental, physical, and behavioural health outcomes [1]. Perceived discrimination has been associated with negative mental health outcomes, such as depressive symptoms $[1,5,6]$, psychiatric distress, poor general wellbeing [1], poor mental health [7], poor sleep [8, 9], poorer cognitive functioning [10], poorer physical health [1], such as poorer self-rated health status $[4,6,11]$, poor self-rated oral health status [4], chronic illness [6], cardiovascular conditions $[4,12]$, respiratory conditions $[4,12]$, pain conditions $[4,12]$, poorer physical functioning or functional limitations [6, 10], multimorbidity [4], and unhealthy behaviours [1], such as smoking [1,9] and alcohol use [1], and increased exposure to the healthcare setting [11].

Most studies investigating the association between perceived discrimination and health outcomes have been conducted in high-income countries, such as in USA, and there has been a lack of studies in low- and middleincome countries, such as in India. Some studies found a high prevalence of everyday perceived discrimination, e.g., in a study among older adults ( $\geq 50$ years) in Brazil, the prevalence everyday perceived discrimination was $16.8 \%$ [13], and among pregnant women in rural Gujarat in India, $67.6 \%$ reported at least one type of everyday perceived discrimination [14]. Gender discrimination has been found associated with poor mental health among women in Bihar, Jharkhand, and Maharashtra in India [15], and everyday perceived discrimination was associated with poorer health status in China [16]. Middleaged and older adults may be at higher risk of being discriminated against due to their decreasing social and financial status [17].

The study aimed to estimate the associations between perceived discrimination and poor physical health, poor mental health, and health risk behaviours in middle-aged and older adults in a national population survey in India. Higher everyday perceived discrimination scores were hypothesized to relate to higher poor physical health, poor mental health, and health risk behaviours.

\section{Methods}

\section{Sample and procedures}

National cross-sectional data from the Longitudinal Aging Study in India (LASI) Wave 1, 2017-2018 were analyzed (individual response rate 87\%) [17]. Face-toface interviews, physical measurement and biomarker data were collected by male and female trained research teams from individuals aged 45 and above and their female spouses, regardless of age, in a household survey from 35 states and union territories of India (excluding Sikkim). Field teams input responses directly into a laptop computer. Details of the sampling strategy have been described elsewhere [17]. Briefly, "LASI adopted a multistage stratified area probability cluster sampling design to arrive at the eventual units of observation: older adults aged 45 and above and their spouses irrespective of age. India is a union comprising 30 states and 6 union territories. Within each state, LASI Wave 1 adopted a three-stage sampling design in rural areas and a fourstage sampling design in urban areas. In each state/ union territories, the first stage involved the selection of Primary Sampling Units (PSUs), that is, subdistricts (Tehsils/Talukas), and the second stage involved the selection of villages in rural areas and wards in urban areas in the selected PSUs. In rural areas, households were selected from selected villages in the third stage. However, sampling in urban areas involved an additional stage. Specifically, in the third stage, one Census Enumeration Block (CEB) was randomly selected in each urban area. In the fourth stage, households were selected from this CEB. Goal was to select a representative sample in each stage of sample selection." [17]. Persons 65 years and older were oversampled by including households with at least one person aged 65 and above to increase the sample size for the elderly age 65 [17]. The Indian Council of Medical Research (ICMR) Ethics Committee approved the study and written/oral informed consent was attained from participants [17].

\section{Measures \\ Outcome variables}

Mental health Life satisfaction was assessed with the item, "Please, think about your life as a whole. How satisfied are you with it? Are you completely satisfied, very satisfied, somewhat satisfied, not very satisfied, or not at all satisfied?" This item was adapted from the Health and Retirement Study [17], and "is a validated singleitem measure of life satisfaction that has been widely used in prior research and correlates strongly with richer, multiple-item life satisfaction measures" $[18,19]$. Responses were grouped into 1 (low) = not very satisfied or not at all satisfied, and $0=$ somewhat satisfied or very satisfied or completely satisfied.

Cognitive functioning was assessed with tests for immediate and delayed word recall, serial $7 \mathrm{~s}$, and orientation based on the Mini-Mental State Exam [20]. A composite score of $0-32$ was computed with a higher score representing better cognitive functioning. 
Insomnia symptoms were assessed with four questions adapted from the Jenkins Sleep Scale (JSS-4) [21]: "How often do you have trouble falling asleep?" 2) "How often do you have trouble with waking up during the night?" 3) "How often do you have trouble with waking up too early and not being able to fall asleep again?" 4) "How often did you feel unrested during the day, no matter how many hours of sleep you had?" Response options were "never, rarely (1-2 nights per week), occasionally (3-4 nights per week), and frequently (5 or more nights per week)"(item 4 was reverse coded). Insomnia problems were "coded as 'frequently' for any of the four symptoms as 1 and 0 for other responses. Participants who scored 1 on any of the four symptoms were considered to have insomnia symptoms." [22]. The "JSS-4 proved excellent reliability and it demonstrated good construct validity." [23]. Internal consistency of the JSS4 was 0.80 in this study.

Depressive symptoms were measured with the Centre for Epidemiological Studies Depression Scale (CES-D10) [24]. The overall scores ranged from zero to 10 and scores of four or more were classified as having depressive symptoms [25]. (Cronbach $\alpha$ was 0.79 in this study).

Pain conditions were assessed with four items. "Have you had any of the following persistent or troublesome problems in past two years?" Back pain or problem, Pain or Stiffness in joints, Pain or Stiffness in joints (Yes/No) and "In the last 12 months, have you ever been diagnosed with or suffered from painful teeth" (Yes/No) [17]. The four pain conditions were summed and used as a binary measure $(1=$ any pain condition and $0=$ no pain condition) in the descriptive table and as a count measure (number of pain conditions) in the Poisson regression model.

Physical health Cardiovascular conditions: Hypertension or raised blood pressure (BP) was defined as "systolic BP $\geq 140 \mathrm{~mm} \mathrm{Hg}$ and/or diastolic BP $\geq 90 \mathrm{~mm} \mathrm{Hg}$ (based on the last two averaged of three readings) or where the participant is currently on antihypertensive medication." [26]. Health care provider diagnosed conditions included 1) Chronic heart diseases such as coronary heart disease (heart attack or Myocardial Infarction), congestive heart failure, or other chronic heart problems, and 2) Stroke [17]. Angina was assessed with the "World Health Organization's Rose angina questionnaire" [27], and defined on the basis of "discomfort at walking uphill or hurrying, or at an ordinary pace on level ground. Furthermore, the pain should be located at the sternum or in the left chest and arm, causing the patient to stop or slow down, and the pain should resolve within 10 minutes when the patient stops or slows down." [28]. The four cardiovascular conditions were summed and used as a binary measure ( 1 = any cardiovascular condition and $0=$ no cardiovascular condition) in the descriptive table and as a count measure (number of cardiovascular conditions) in the Poisson regression model. Chronic lung disease such as "asthma, chronic obstructive pulmonary disease/ chronic bronchitis, or other chronic lung problems" was assessed by self-reported health care provider diagnosis (Yes/No) [17]. Functional limitations were assessed with Activities of Daily Living (ADL) (6 items) and Instrumental Activities of Daily Living (IADL) (7 items) (Yes, No) $[29,30]$. Cronbach alpha was 0.87 for ADL and 0.90 for IADL in this study. Responses were dichotomized into $0-1$ and $\geq 2$ ADL and IADL items.

Health risk behaviours Current tobacco smoking was sourced from the item, "Do you currently smoke any tobacco products (cigarettes, bidis, cigars, hookah, cheroot, etc.)?" (Yes, No) [17]. Heavy episodic alcohol use was assessed with the question, "In the last 3 months, how frequently on average, have you had at least 5 or more drinks on one occasion?" [17] and defined as "one to three days per month, one to four days per week, five or more days per week, or daily." Physical inactivity was defined as hardly ever or never engaging in vigorous or moderate physical activity [17].

\section{Exposure variable}

Discrimination experiences were assessed with the sixitem Everyday Discrimination Scale (EDS) (Short version) [6]. The EDS measures subjective experiences of discrimination, defined as "the belief that one has experienced unfair treatment by individuals and social institutions, and that this treatment was based on personal characteristics such as race, gender, or weight" [31]. The wording of each item, e.g., "treated with less courtesy or respect," are shown in Table 2). Response options ranged from $1=$ "never" to $6=$ "almost every day" were dichotomised to 'never' $=0$ and 'ever' (collapsing those reporting 'less than once a year' or greater into one category) $=1$, summed with total scores from 0 to 6 , and trichotomized into $0=1$ no, $1-2=2$ moderate and 3$6=3$ high discrimination; Cronbach's alpha for the EDS in this study was 0.86. Participants that responded affirmative to any discrimination question were asked a follow-up question inquiring into the potential reasons for discrimination. Response options were "age, gender, religion, caste, weight, physical disability, other aspects of physical appearance, financial status, and others." [6].

Covariates consisted of education (none and $\geq 1$ years), age, sex (male, female), marital status (currently married vs. widowed/divorced/separated/deserted/live-in relationship/never married), caste (Scheduled tribes, scheduled castes, other backward classes, and one of these) urban and rural residence [17]. Scheduled tribes, scheduled castes, and other backward classes have been 
historically disadvantaged due to various socio-economic factors like wealth or traditional occupation and are given reservation by the government of India [32].

Subjective socioeconomic status was assessed with the question, "Please imagine a ten-step ladder, where at the bottom are the people who are the worst off - who have the least money, least education, and the worst jobs or no jobs, and at the top of the ladder are the people who are the best off - those who have the most money, most education, and best jobs. Please indicate the number (110 ) on the rung on the ladder where you would place yourself." [17]. Steps 1 to 3 on the socioeconomic ladder were defined as low, 4-5 as medium, and 6-10 as high.

Organizational religiosity was assessed with the question, "In the past year, how often have you attended religious services (at a temple/mosque/church, etc.)?" Response options were grouped into $1(\mathrm{low})=$ not at all, 2 (medium) $=1-3$ times a month or 1 or more times a year, and 3 (high) $=$ once a week or more than once a week or every day [17].

Social participation was measured with 6 items, e.g., "Eat-out-of-house (restaurant/hotel)" [33]. Responses were coded $1=$ daily to at least once a month and $0=$ rarely/once a year or never, and social participation was defined as at least one activity [33].

\section{Data analysis}

Sampling weights applied to account for both study design (stratification) and non-response. Considering the clustered study design, data analyses were conducted with "STATA software version 15.0 (Stata Corporation, College Station, TX, USA)." Logistic, linear and Poisson regression analyses were used to calculate associations between moderate and high perceived discrimination as well as attribution of discrimination, and binary, scale and count outcome variables. Odds ratios and 95 Confidence Intervals (CI) are presented for logistic regression analyses, exponential Coefficients and 95\% CI for linear regression, and Incident Risk Ratios and 95\% CI for Poison regression analyses. The first multivariable models (Model 1) were adjusted for age group, and sex, and in the second multivariable models (Model 2) adjustments were made for age group, sex, education, marital status, subjective socioeconomic status, area of residence, caste/tribe, social participation, organised religiosity, and all health indicators assessed in this study. Sociodemographic and social covariates were selected based on a previous literature review $[1,12]$. $P$-values of below 0.05 were accepted as significant and missing values were excluded from the analysis.

\section{Results}

\section{Sample characteristics}

The sample included 72,262 middle-aged and older adults (45 years and older), 58.0\% were female and $42.0 \%$ male. Almost half of the participants (49.5\%) had no formal education, $75.6 \%$ were married, and $68.2 \%$ were residing in rural areas. One in five $(24.1 \%)$ of the participants rated their socioeconomic status as high, $27.6 \%$ attended at least weekly religious services, and $54.4 \%$ had social participation. Furthermore, health indictor characteristics are shown in Table 1 (see Table 1).

\section{Proportions of perceived discrimination and reasons}

The prevalence of moderate (1-2 types) perceived discrimination was $10.7 \%$, and high (3-6 types) perceived discrimination was $6.6 \%$. Among those participants who reported having experienced discrimination, the perceived reasons were age $48.9 \%$, financial status $41.8 \%$, caste $12.9 \%$, gender $9.3 \%$, other $8.9 \%$, other aspects of physical appearance $6.3 \%$, religion $5.3 \%$, physical disability $3.9 \%$, and weight $1.6 \%$ (see Table 2 ).

\section{Associations of moderate and high perceived discrimination with health outcome indicators}

In the final adjusted logistic, linear or Poisson regression analyses, moderate and/or high perceived discrimination was significantly positively associated with poor mental health (low life satisfaction, poor cognitive functioning, insomnia symptoms, and depressive symptoms), pain conditions count, functional limitations, and health risk behaviours (heavy episodic drinking and physical inactivity). High perceived discrimination was in the first model adjusted for age and sex associated with current tobacco use, while no associations were found for cardiovascular conditions count and chronic lung disease (see Table 3).

\section{Associations between reasons of discrimination and health outcomes}

In the final adjusted logistic or Poisson regression models, perceived age and/or financial discrimination were positively associated with low life satisfaction, depressive symptoms, pain conditions, and physical inactivity. In addition, caste/tribe was positively associated with functional limitations and depressive symptoms (see Table 4).

\section{Discussion}

The study aimed to estimate the associations between perceived discrimination, poor physical health, poor mental health, and health risk behaviours in middle-aged and older adults in a national population survey in India in 2017-2018. Results show for the first time that perceived discrimination is associated with poor mental health (low life satisfaction, poor cognitive functioning, insomnia symptoms, and depressive symptoms), poor physical health (pain conditions, and functional limitations), and health risk behaviours (heavy episodic drinking and physical inactivity) in middle-aged and older 
Table 1 Sample characteristics among middle-aged and older adults in India, 2017-2018 (N=72,262)

\begin{tabular}{|c|c|c|c|c|c|c|}
\hline \multirow[t]{2}{*}{ Variable } & \multirow[t]{2}{*}{ Variable specification } & \multirow{2}{*}{$\begin{array}{l}\text { Sample } \\
\text { \% or M } \\
\text { (SD) }\end{array}$} & \multirow{2}{*}{$\begin{array}{l}\text { Discrimination } \\
\geq 1 \text { vs } 0 \text { ) }\end{array}$} & \multicolumn{3}{|c|}{$\begin{array}{l}\text { Attribution of } \\
\text { discrimination }\end{array}$} \\
\hline & & & & Age & Financial & Other \\
\hline \multicolumn{7}{|l|}{ Social and demographic factors } \\
\hline \multirow[t]{2}{*}{ Age in years } & $45-59$ & 54.1 & 17.0 & 6.3 & 7.7 & 7.6 \\
\hline & 60 or more & 45.9 & 17.6 & 10.8 & 6.4 & 6.4 \\
\hline \multirow[t]{2}{*}{ Sex } & Female & 58.0 & 17.0 & 8.2 & 7.2 & 6.9 \\
\hline & Male & 42.0 & 17.7 & 8.5 & 7.0 & 7.3 \\
\hline \multirow[t]{2}{*}{ Education } & $\geq 1$ years schooling & 50.5 & 15.1 & 6.5 & 5.8 & 6.4 \\
\hline & No schooling & 49.5 & 19.5 & 10.2 & 8.5 & 7.7 \\
\hline \multirow[t]{3}{*}{ Subjective socioeconomic status } & Low & 37.2 & 21.6 & 10.3 & 10.4 & 8.8 \\
\hline & Medium & 38.7 & 15.8 & 7.0 & 6.2 & 6.5 \\
\hline & High & 24.1 & 13.1 & 7.3 & 3.6 & 5.1 \\
\hline \multirow[t]{2}{*}{ Marital status } & Not married & 24.4 & 18.9 & 11.4 & 7.7 & 6.4 \\
\hline & Married & 75.6 & 16.8 & 7.3 & 6.9 & 7.2 \\
\hline \multirow[t]{4}{*}{ Caste/tribe } & None of the below & 24.9 & 14.0 & 7.3 & 5.2 & 5.4 \\
\hline & Scheduled caste & 8.8 & 19.3 & 8.8 & 9.2 & 8.4 \\
\hline & Scheduled tribe & 19.7 & 16.5 & 8.3 & 5.9 & 7.0 \\
\hline & Other backward class & 46.7 & 18.8 & 8.9 & 7.6 & 7.5 \\
\hline \multirow[t]{2}{*}{ Residence } & Rural & 68.2 & 18.1 & 8.8 & 7.8 & 7.0 \\
\hline & Urban & 31.8 & 15.6 & 7.2 & 5.6 & 7.0 \\
\hline \multirow{3}{*}{$\begin{array}{l}\text { Organised religiosity (Attendance of religious } \\
\text { services) }\end{array}$} & Not at all & 25.5 & 15.4 & 7.8 & 5.5 & 6.9 \\
\hline & $\begin{array}{l}1-3 \text { times/month or } \geq 1 \text { times/ } \\
\text { year }\end{array}$ & 46.9 & 17.2 & 8.3 & 7.6 & 6.9 \\
\hline & $\geq 1 /$ week or every day & 27.6 & 19.1 & 8.9 & 7.8 & 7.4 \\
\hline Social participation & Yes & 54.4 & 19.4 & 9.1 & 7.9 & 8.3 \\
\hline \multicolumn{7}{|l|}{ Mental health } \\
\hline Life satisfaction & Low & 11.1 & 29.6 & 13.6 & 15.7 & 12.3 \\
\hline Cognitive functioning & Scale (0-32): M (SD) & $18.7(5.1)$ & $17.8(5.2)$ & $\begin{array}{l}12.3 \\
(5.3)\end{array}$ & $17.6(5.1)$ & $\begin{array}{l}17.8 \\
(5.2)\end{array}$ \\
\hline Insomnia symptoms & Yes & 12.7 & 26.4 & 13.8 & 11.3 & 9.5 \\
\hline Depressive symptoms & Yes & 27.6 & 28.9 & 14.3 & 13.3 & 11.8 \\
\hline \multicolumn{7}{|l|}{ Physical health } \\
\hline Any pain conditions & 1 or more & 65.7 & 19.3 & 9.5 & 8.1 & 7.9 \\
\hline Back pain or problem & Yes & 31.5 & 20.8 & 10.0 & 9.1 & 8.1 \\
\hline Persistent headaches & Yes & 12.8 & 21.9 & 9.5 & 11.1 & 8.6 \\
\hline Painful teeth & Yes & 28.4 & 21.5 & 10.4 & 8.7 & 9.7 \\
\hline Pain or stiffness of joints & Yes & 46.1 & 20.2 & 10.2 & 8.6 & 8.2 \\
\hline Any cardiovascular conditions & 1 or more & 46.6 & 16.7 & 8.5 & 6.8 & 6.8 \\
\hline Hypertension & Yes & 40.4 & 16.0 & 8.4 & 6.3 & 6.5 \\
\hline Angina & Yes & 8.6 & 19.9 & 8.6 & 9.7 & 7.5 \\
\hline Heart disease & Yes & 8.6 & 14.2 & 7.6 & 5.8 & 5.2 \\
\hline Stoke & Yes & 1.8 & 22.7 & 13.5 & 6.7 & 12.8 \\
\hline Chronic lung disease & Yes & 6.3 & 19.7 & 11.5 & 8.3 & 7.3 \\
\hline Functional limitations ${ }^{a}$ & 2 or more & 28.8 & 22.1 & 11.6 & 8.6 & 9.3 \\
\hline
\end{tabular}


Table 1 Sample characteristics among middle-aged and older adults in India, 2017-2018 (N=72,262) (Continued)

\begin{tabular}{|c|c|c|c|c|c|c|}
\hline \multirow[t]{2}{*}{ Variable } & \multirow[t]{2}{*}{ Variable specification } & \multirow{2}{*}{$\begin{array}{l}\text { Sample } \\
\text { \% or M } \\
\text { (SD) }\end{array}$} & \multirow{2}{*}{$\begin{array}{l}\text { Discrimination } \\
\geq 1 \text { vs } 0)\end{array}$} & \multicolumn{3}{|c|}{$\begin{array}{l}\text { Attribution of } \\
\text { discrimination }\end{array}$} \\
\hline & & & & Age & Financial & Other \\
\hline Current tobacco smoking & Yes & 30.4 & 19.1 & 9.6 & 8.3 & 7.0 \\
\hline Heavy episodic drinking & Yes & 2.9 & 24.8 & 13.4 & 10.2 & 11.5 \\
\hline Physical inactivity & Yes & 23.7 & 20.1 & 11.2 & 5.7 & 7.5 \\
\hline
\end{tabular}

${ }^{\mathrm{a} D i f f i c u l t i e s ~ w i t h ~ t w o ~ o r ~ m o r e ~ A c t i v i t i e s ~ o f ~ D a i l y ~ L i v i n g ~(A D L) ~ a n d ~ I n s t r u m e n t a l ~ A c t i v i t i e s ~ o f ~ D a i l y ~ L i v i n g ~(I A D L) ~}$

adults in India. This was found after adjusting for relevant confounders, including age group, sex, education, marital status, subjective socioeconomic status, area of residence, social participation, organised religiosity, and all health variables assessed in this study. These results are consistent with previous research [1,4-12] in highincome countries. Generally, perceived discrimination associations were stronger on mental than physical health, which concurs with previous observations [7].

The association between perceived discrimination with poor mental health (low life satisfaction, poor cognitive functioning, insomnia symptoms, and depressive symptoms), is possibly confirming a direct pathway from increases in perceived discrimination to more negative mental health outcomes, as found in predominantly high-income countries [1]. Everyday discrimination may act as micro-aggressors believed to lead to defensive anxiety and a state of chronic stress, leading to poorer mental health over time [10]. In addition, persons with perceived discrimination may activate a stereotype thread, in particular age-based stereotype threat, which was found among older adults to have led to decreased performance in cognition tests [10,34].

Possible mechanisms relate to perceived discrimination as stressors that are uncontrollable and unpredictable and thus detrimental to health, initiating a process of physiological responses, such as increased cortisol secretion, heart rate, blood pressure, chronic pain, respiratory problems, and functional limitations which overtime negatively impact health $[1,10,12,31]$. However, in our study we only found associations between perceived discrimination and pain condition counts and functional limitations, but not with cardiovascular condition count and respiratory problems or chronic lung disease, as found in some previous studies [4, 35].

Regarding health risk behaviours, this study found an association between perceived discrimination and heavy episodic drinking, physical inactivity, and in the not fully adjusted analysis tobacco smoking. Perceived discrimination may reduce self-control capabilities, potentially

Table 2 Proportions of perceived discrimination and reasons

\begin{tabular}{|c|c|c|}
\hline \multirow[t]{6}{*}{ Perceived discrimination } & Treated with less courtesy or respect. & 12.1 \\
\hline & Poorer service at restaurants or stores. & 6.7 \\
\hline & People act as if they think you are not smart. & 8.1 \\
\hline & People act as if they are afraid of you. & 5.1 \\
\hline & You are threatened or harassed. & 6.4 \\
\hline & Poorer medical services or treatment. & 5.9 \\
\hline \multirow[t]{3}{*}{ Number of perceived discriminations } & 0 & 82.7 \\
\hline & $1-2$ & 10.7 \\
\hline & $3-6$ & 6.6 \\
\hline \multirow[t]{9}{*}{ Reasons of discrimination } & Age & 8.3 \\
\hline & Financial & 7.1 \\
\hline & Caste & 2.2 \\
\hline & Gender & 1.6 \\
\hline & Physical appearance & 1.1 \\
\hline & Religion & 0.9 \\
\hline & Physical disability & 0.7 \\
\hline & Body weight & 0.3 \\
\hline & Other & 1.5 \\
\hline
\end{tabular}


Table 3 Associations between perceived discrimination and health indicators

\begin{tabular}{|c|c|c|c|c|}
\hline Outcome variables & $\begin{array}{l}\text { Response } \\
\text { format }\end{array}$ & $\begin{array}{l}\text { Perceived } \\
\text { discrimination }\end{array}$ & 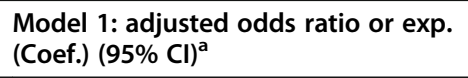 & $\begin{array}{l}\text { Model 2: adjusted odds ratio, IRR, or } \\
\text { exp. (Coef.) }(95 \% \mathrm{Cl})^{\mathbf{b}}\end{array}$ \\
\hline \multicolumn{5}{|l|}{ Mental health } \\
\hline \multirow[t]{3}{*}{ Low life satisfaction } & No & No & 1 Reference & 1 Reference \\
\hline & Yes & Moderate & $2.11(1.73,2.58)^{* * *}$ & $1.47(1.28,1.68)^{* * *}$ \\
\hline & & Severe & $2.48(2.13,2.89)^{* * *}$ & $1.42(1.20,1.67)^{* * *}$ \\
\hline \multirow[t]{3}{*}{ Cognitive functioning } & Scale & No & 1 Reference & 1 Reference \\
\hline & & Moderate & $0.39(0.28,0.54)^{* * *}$ & $0.60(0.49,0.74)^{* * *}$ \\
\hline & & Severe & $0.29(0.20,0.42)^{* * *}$ & $0.71(0.55,0.93)^{*}$ \\
\hline \multirow[t]{3}{*}{ Insomnia symptoms } & No & No & 1 Reference & 1 Reference \\
\hline & Yes & Moderate & $1.73(1.50,2.00)^{* * *}$ & $1.45(1.25,1.57)^{* * *}$ \\
\hline & & Severe & $2.15(1.84,2.51)^{* * *}$ & $1.43(1.22,1.69)^{* * *}$ \\
\hline \multirow[t]{3}{*}{ Depressive symptoms } & No & No & 1 Reference & 1 Reference \\
\hline & Yes & Moderate & $1.91(1.64,2.22)^{* * *}$ & $1.40(1.18,1.65)^{* * *}$ \\
\hline & & Severe & $5.02(4.47,6.62)^{* * *}$ & $4.14(3.62,4.74)^{* * *}$ \\
\hline \multicolumn{5}{|l|}{ Physical health } \\
\hline \multirow{3}{*}{$\begin{array}{l}\text { Number of pain } \\
\text { conditions }\end{array}$} & Count & No & 1 Reference & 1 Reference \\
\hline & & Moderate & $1.20(1.08,1.32)^{* * *}$ & $1.06(1.00,1.12)^{*}$ \\
\hline & & Severe & $1.36(1.30,1.44)^{* * *}$ & $1.19(1.13,1.26)^{* * *}$ \\
\hline \multirow{3}{*}{$\begin{array}{l}\text { Number of } \\
\text { cardiovascular } \\
\text { conditions }\end{array}$} & Count & No & 1 Reference & 1 Reference \\
\hline & & Moderate & $0.94(0.87,1.01)$ & $0.93(0.87,1.00)$ \\
\hline & & Severe & $1.01(0.94,1.09)$ & $0.99(0.92,1.06)$ \\
\hline \multirow[t]{3}{*}{ Chronic lung disease } & No & No & 1 Reference & 1 Reference \\
\hline & Yes & Moderate & $1.24(0.97,1.58)$ & $1.21(0.93,1.57)$ \\
\hline & & Severe & $1.08(0.88,1.31)$ & $1.01(0.83,1.23)$ \\
\hline \multirow[t]{3}{*}{ Functional limitations ${ }^{c}$} & No & No & 1 Reference & 1 Reference \\
\hline & Yes & Moderate & $1.75(1.53,2.01)^{* * *}$ & $1.55(1.35,1.78)^{* * *}$ \\
\hline & & Severe & $1.44(1.25,1.65)^{* * *}$ & $1.15(1.00,1.33)^{*}$ \\
\hline \multicolumn{5}{|l|}{ Health risk behaviour } \\
\hline \multirow{3}{*}{$\begin{array}{l}\text { Current tobacco } \\
\text { smoking }\end{array}$} & No & No & 1 Reference & 1 Reference \\
\hline & Yes & Moderate & $1.04(0.87,1.26)$ & $1.01(0.87,1.16)$ \\
\hline & & Severe & $1.29(1.11,1.49)^{* * *}$ & $1.13(0.97,1.33)$ \\
\hline \multirow[t]{3}{*}{ Heavy episodic drinking } & No & No & 1 Reference & 1 Reference \\
\hline & Yes & Moderate & $1.29(0.99,1.67)$ & $1.31(1.01,1.70)^{*}$ \\
\hline & & Severe & $2.05(1.33,3.15)^{* * *}$ & $1.66(1.25,2.20)^{* * *}$ \\
\hline \multirow[t]{3}{*}{ Physical inactivity } & No & No & 1 Reference & 1 Reference \\
\hline & Yes & Moderate & $1.06(0.91,1.24)$ & $1.06(0.90,1.25)$ \\
\hline & & Severe & $1.67(1.44,1.94)^{* * *}$ & $1.61(1.37,1.89)^{* * *}$ \\
\hline
\end{tabular}

Cl Confidence Interval; ${ }^{* * *} p<0.001 ;{ }^{* *} p<0.01 ;{ }^{*} p<0.05 ;{ }^{a}$ Adjusted for age group, and sex, ${ }^{\mathrm{b}}$ Adjusted for age group, sex, education, marital status, subjective socioeconomic status, area of residence, caste/tribe, social participation, organised religiosity, and all other variables in the table; ${ }^{c}$ Difficulties with two or more Activities of Daily Living (ADL) and Instrumental Activities of Daily Living (IADL), IRR Incident Risk Ratio

increasing different types of health risk behaviours [1]. For example, individuals with perceived discrimination may cope with this stressor by "self-medication" with heavy drinking and/or using nicotine [9]. In addition, "It is possible that people who use tobacco and/or alcohol products do so to strengthen social relationships with other substance users." [36].

Among nine attributions of discrimination, the highest were age and financial, with a lower rate of caste and gender discrimination and the lowest physical disability 
Table 4 Associations between reasons of discrimination and selected health outcomes

\begin{tabular}{|c|c|c|c|}
\hline Outcome variables & $\begin{array}{l}\text { Attribution of } \\
\text { discrimination }\end{array}$ & $\begin{array}{l}\text { Model 1: adjusted odds ratio or IRR (95\% } \\
\text { Cl) }^{\mathrm{a}}\end{array}$ & $\begin{array}{l}\text { Model 2: adjusted odds ratio or IRR }(95 \% \\
\text { CI) }^{\text {b }}\end{array}$ \\
\hline \multicolumn{4}{|l|}{ Mental health } \\
\hline \multirow[t]{5}{*}{ Low life satisfaction } & No discrimination & 1 Reference & 1 Reference \\
\hline & Age & $1.30(1.09,1.55)^{* *}$ & $1.25(1.06,1.47)^{* *}$ \\
\hline & Financial & $2.66(2.31,3.06)^{* * *}$ & $2.33(2.00,2.72)^{* * *}$ \\
\hline & Caste & $1.43(1.12,1.85)^{* *}$ & $1.12(0.85,1.48)$ \\
\hline & Gender & $1.06(0.71,1.60)$ & $0.94(0.55,1.63)$ \\
\hline \multirow[t]{5}{*}{ Depressive symptoms } & No discrimination & 1 Reference & 1 Reference \\
\hline & Age & $1.91(1.70,2.15)^{* * *}$ & $1.72(1.50,1.96)^{* * *}$ \\
\hline & Financial & $2.45(2.17,2.76)^{* * *}$ & $2.07(1.81,2.36)^{* * *}$ \\
\hline & Caste & $1.59(1.22,2.07)^{* * *}$ & $1.76(1.43,2.17)^{* * *}$ \\
\hline & Gender & $1.36(0.90,2.05)$ & $1.14(0.67,1.94)$ \\
\hline \multicolumn{4}{|l|}{ Physical health } \\
\hline \multirow{5}{*}{$\begin{array}{l}\text { Number of pain } \\
\text { conditions }\end{array}$} & No discrimination & Reference & Reference \\
\hline & Age & $1.12(1.05,1.18)^{* * *}$ & $1.08(1.02,1.14)^{* *}$ \\
\hline & Financial & $1.23(1.16,1.31)^{* * *}$ & $1.15(1.08,1.23)^{* * *}$ \\
\hline & Caste & $1.13(1.01,1.27)^{*}$ & $0.98(0.91,1.06)$ \\
\hline & Gender & $1.03(0.91,1.16)$ & $1.02(0.93,1.12)$ \\
\hline \multirow[t]{5}{*}{ Functional limitations ${ }^{c}$} & No discrimination & 1 Reference & 1 Reference \\
\hline & Age & $1.39(1.20,1.61)^{* * *}$ & $1.23(1.07,1.43)^{* *}$ \\
\hline & Financial & $1.36(1.20,1.55)^{* * *}$ & $1.21(1.06,1.39)^{* *}$ \\
\hline & Caste & $1.12(1.02,1.23)^{*}$ & $1.15(1.04,1.28)^{* *}$ \\
\hline & Gender & $1.31(0.74,2.32)$ & $1.21(1.06,1.39)$ \\
\hline \multicolumn{4}{|l|}{ Health risk behaviour } \\
\hline \multirow[t]{5}{*}{ Physical inactivity } & No discrimination & 1 Reference & 1 Reference \\
\hline & Age & $1.54(1.33,1.77)^{* * *}$ & $1.47(1.27,1.69)^{* * *}$ \\
\hline & Financial & $0.69(0.60,0.80)^{* * *}$ & $0.68(0.59,0.76)^{* * *}$ \\
\hline & Caste & $0.98(0.80,1.18)$ & $0.91(0.79,1.03)$ \\
\hline & Gender & $0.67(0.43,1.05)$ & $0.68(0.44,1.07)$ \\
\hline
\end{tabular}

Cl Confidence Interval; ${ }^{* * *} p<0.001 ;{ }^{* *} p<0.01 ;{ }^{*} p<0.05 ;{ }^{a}$ Adjusted for age group, and sex, ${ }^{\mathrm{b}}$ Adjusted for age group, sex, education, marital status, subjective socioeconomic status, area of residence, caste/tribe, social participation, organised religiosity, and all health variables; ${ }^{\mathrm{c}} \mathrm{Difficulties}$ with two or more Activities of Daily Living (ADL) and Instrumental Activities of Daily Living (IADL), IRR Incident Risk Ratio

and body weight discrimination, and age and financial discrimination were associated with almost all health outcomes in this study. In comparison, in USA, the four most common reasons for perceived discrimination were race-ethnicity, gender, various aspects of appearance (predominantly weight), and age [37], and in European countries [38], the highest was age discrimination, followed by gender and ethnic discrimination. Our results seem to mean that discrimination primarily affects the age and materially disadvantaged population in India. A previous study among older adults India showed that lower socioeconomic status (subjective socioeconomic status, food insecurity, and no education) was associated with discrimination experiences [39], may be because of higher exposure to discriminatory situations [40], and belonging to lower castes (scheduled tribes and other backward classes) [14]. Moreover, studies have shown that economic, caste and gender inequality negatively impacts on health outcomes [41], selfreported morbidity and untreated morbidity [42], and violence [43] among adults and older adults in India, emphasizing the need for "social and economic support should be given to the economically vulnerable older population." [43]. In contrast, in many American studies race-based chronic discrimination (both actual and perceived) is the focus setting into "motion, a process of physiological responses (e.g., elevated blood pressure and heart rate, production of biochemical reactions, hypervigilance) that eventually result in disease and mortality." [44]. 


\section{Strength and limitations of the study}

Study strengths included the use of standardized measures adapted from the Health and Retirement Study and a large, nationally representative sample of middleaged and older adults in India. The self-report of most data may have their limitations. It is possible that participants underreported everyday discrimination experiences, and some chronic conditions were not verified by clinical diagnosis. Although these events are not objective observed discrimination, they can be considered as a form of stress [1]. Due to the cross-sectional design of the study, we were unable to determine the direction of the assessed associations. Some variables, such as dietary behaviour, were not assessed and should be included in future studies. A further limitation was that the role of structural discrimination was not assessed. It is likely that people who experience everyday discrimination are also experiencing structural discrimination. Another study limitation was that we have no information about whether the study sample has good representation of groups of people who are historically under-represented in research studies, such as those of lower casts or socioeconomic status groups.

\section{Conclusions}

The study largely extents existing evidence from highincome countries that have shown associations between perceived discrimination and low life satisfaction, poor cognitive functioning, insomnia symptoms, depressive symptoms, pain conditions, functional limitations, heavy episodic drinking and physical inactivity among middleaged and older adults in India. It would be important to address perceived discrimination in Indian society, and by using such measures, harmful effects of discrimination on mental health, cognitive functioning, pain conditions, functional limitations, and health risk behaviours could be reduced at an early stage.

\section{Abbreviations}

ADL: Activities of Daily Living; BMl: Body Mass Index; CES-D: Center for Epidemiologic Studies Depression Scale; EDS: Everyday Discrimination Scale; IADL: Instrumental Activities of Daily Living; LASI: Longitudinal Aging Study in India

\section{Acknowledgements}

The Longitudinal Aging Study in India Project is funded by the Ministry of Health and Family Welfare, Government of India, the National Institute on Aging (R01 AG042778, R01 AG030153), and United Nations Population Fund, India.

\section{Authors' contributions}

All authors fulfil the criteria for authorship. SP and KP conceived and designed the research, performed statistical analysis, drafted the manuscript, and made critical revisions of the manuscript for key intellectual content. All authors read and approved the final version of the manuscript and have agreed to the authorship and order of authorship for this manuscript.

\section{Funding}

The analysis received no funding.
Availability of data and materials

The data are available at the The Gateway to Global Aging Data (www.g2aging.org).

\section{Declarations}

All methods were carried out in accordance with relevant guidelines and regulations.

Ethics approval and consent to participate

The study was approved by the Indian Council of Medical Research (ICMR) Ethics Committee and written/oral informed consent was obtained from participants.

Consent for publication

Not applicable.

\section{Competing interests}

The authors declare that they have no competing interests.

\section{Author details}

${ }^{1}$ ASEAN Institute for Health Development, Mahidol University, Salaya, Phutthamonthon, Nakhon Pathom, Thailand. ${ }^{2}$ Department of Research Administration and Development, University of Limpopo, Turfloop, Polokwane, South Africa. ${ }^{3}$ Department of Psychology, College of Medical and Health Science, Asia University, Taichung, Taiwan.

Received: 11 April 2021 Accepted: 29 September 2021

Published online: 18 October 2021

References

1. Pascoe EA, Smart RL. Perceived discrimination and health: a meta-analytic review. Psychol Bull. 2009;135(4):531-54. https://doi.org/10.1037/a0016059.

2. Mouzon DM, Taylor RJ, Woodward A, Chatters LM. Everyday racial discrimination, everyday non-racial discrimination, and physical health among African Americans. J Ethn Cult Divers Soc Work. 2017;26(1-2):68-80. https://doi.org/10.1080/15313204.2016.1187103.

3. Williams DR, Lawrence JA, Davis BA, Vu C. Understanding how discrimination can affect health. Health Serv Res. 2019;54 Suppl 2(Suppl 2): 1374-88. https://doi.org/10.1111/1475-6773.13222.

4. Krieger N. Methods for the scientific study of discrimination and health: an ecosocial approach. Am J Public Health. 2012;102(5):936-44. https://doi. org/10.2105/AJPH.2011.300544.

5. Mouzon DM, Taylor RJ, Keith VM, Nicklett EJ, Chatters LM. Discrimination and psychiatric disorders among older African Americans. Int J Geriatr Psychiatry. 2017:32(2):175-82. https://doi.org/10.1002/gps.4454.

6. Sternthal M, Slopen N, Williams DR. Racial disparities in health: how much does stress really matter? Du Bois Review. 2011;8(1):95-113. https://doi.org/1 $0.1017 /$ S1742058X11000087.

7. Andrade N, Ford AD, Alvarez C. Discrimination and Latino health: a systematic review of risk and resilience. Hisp Health Care Int. 2021;19(1):516. https://doi.org/10.1177/1540415320921489.

8. Lewis TT, Troxel WM, Kravitz HM, Bromberger JT, Matthews KA, Hall MH. Chronic exposure to everyday discrimination and sleep in a multiethnic sample of middle-aged women. Health Psychol. 2013;32(7):810-9. https:// doi.org/10.1037/a0029938.

9. Sims M, Diez-Roux AV, Gebreab SY, Brenner A, Dubbert $P$, Wyatt $S$, et al. Perceived discrimination is associated with health behaviours among African-Americans in the Jackson heart study. J Epidemiol Community Health. 2016;70(2):187-94. https://doi.org/10.1136/jech-2015-206390.

10. Shankar A, Hinds P. Perceived discrimination: associations with physical and cognitive function in older adults. Health Psychol. 2017;36(12):1126-34. https://doi.org/10.1037/hea0000522.

11. Fazeli Dehkordy S, Hall KS, Dalton VK, Carlos RC. The link between everyday discrimination, healthcare utilization, and health status among a National Sample of women. J Women's Health (Larchmt). 2016;25(10):1044-51. https://doi.org/10.1089/jwh.2015.5522.

12. Gee GC, Spencer MS, Chen J, Takeuchi D. A nationwide study of discrimination and chronic health conditions among Asian Americans. Am J Public Health. 2007 Jul:97(7):1275-82. https://doi.org/10.2105/AJPH.2006.091 827. 
13. Braga LS, Caiaffa WT, Ceolin APR, de Andrade FB, Lima-Costa MF. Perceived discrimination among older adults living in urban and rural areas in Brazil: a national study (ELSI-Brazil). BMC Geriatr. 2019;19(1):67. https://doi.org/10.11 86/s12877-019-1076-4

14. Khubchandani J, Soni A, Fahey N, Raithatha N, Prabhakaran A, Byatt N, et al. Caste matters: perceived discrimination among women in rural India. Arch Womens Ment Health. 2018;21(2):163-70. https://doi.org/10.1007/s00737-01 7-0790-1.

15. Hathi P, Coffey D, Thorat A, Khalid N. When women eat last: discrimination at home and women's mental health. PLoS One. 2021 Mar 2;16(3):e0247065. https://doi.org/10.1371/journal.pone.0247065.

16. Lin D, Li X, Wang B, Hong $Y$, Fang $X$, Qin $X$, et al. Discrimination, perceived social inequity, and mental health among rural-to-urban migrants in China. Community Ment Health J. 2011:47(2):171-80. https://doi.org/10.1007/s1 0597-009-9278-4.

17. International Institute for Population Sciences (IIPS), NPHCE, MoHFW, Harvard T. H. Chan School of Public Health (HSPH) and the University of Southern California (USC). Longitudinal ageing study in India (LASI) wave 1, 2017-18, India report. Mumbai: International Institute for Population Sciences; 2020.

18. Cheung F, Lucas RE. Assessing the validity of single-item life satisfaction measures: results from three large samples. Qual Life Res. 2014;23(10):280918. https://doi.org/10.1007/s11136-014-0726-4.

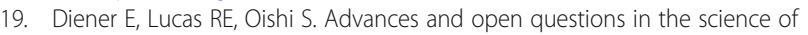
subjective well-being. Collabra Psychol. 2018;4(1, 15):1-49.

20. Lee J, Smith JP. Regional disparities in adult height, educational attainment and gender difference in late- life cognition: findings from the longitudinal aging study in India (LASI). J Econ Ageing. 2014;4:26-34. https://doi.org/10.1 016/j.jeoa.2014.02.002.

21. Jenkins CD, Stanton BA, Niemcryk SJ, Rose RM. A scale for the estimation of sleep problems in clinical research. J Clin Epidemiol. 1988;41(4):313-21. https://doi.org/10.1016/0895-4356(88)90138-2.

22. Cho E, Chen TY. The bidirectional relationships between effort-reward imbalance and sleep problems among older workers. Sleep Health. 2020; 6(3):299-305. https://doi.org/10.1016/j.sleh.2020.01.008.

23. Fabbri M, Beracci A, Martoni M, Meneo D, Tonetti L, Natale V. Measuring subjective sleep quality: a review. Int J Environ Res Public Health. 2021;18(3): 1082. https://doi.org/10.3390/ijerph18031082.

24. Andresen EM, Malmgren JA, Carter WB, Patrick DL. Screening for depression in well older adults: evaluation of a short form of the CES-D (Center for Epidemiologic Studies Depression Scale). Am J Prev Med. 1994;10(2):77-84 https://doi.org/10.1016/S0749-3797(18)30622-6.

25. Kumar S, Nakulan A, Thoppil SP, Parassery RP, Kunnukattil SS. Screening for Depression among Community-dwelling Elders: Usefulness of the Center for Epidemiologic Studies Depression Scale. Indian J Psychol Med. 2016;38(5): 483-5. https://doi.org/10.4103/0253-7176.191380.

26. Chobanian AV, Bakris GL, Black HR, et al. Seventh report of the Joint National Committee of Prevention, Detection, Evaluation, and Treatment of High Blood Pressure. Hypertension. 2003;42(6):1206-52. https://doi.org/10.11 61/01.HYP.0000107251.49515.c2.

27. Rose GA. The diagnosis of ischaemic heart pain and intermittent claudication in field surveys. Bull World Health Organ. 1962;27:645-58.

28. Achterberg S, Soedamah-Muthu SS, Cramer MJ, Kappelle LJ, van der Graaf Y, Algra A, et al. Prognostic value of the Rose questionnaire: a validation with future coronary events in the SMART study. Eur J Prev Cardiol. 2012;19(1):514. https://doi.org/10.1177/1741826710391117 Epub 2011 Feb 22. PMID: 21450623.

29. Katz S, Ford AB, Moskowitz RW, Jackson BA, Jaffe MW. Studies of illness in the aged the index of adl: a standardized measure of biological and psychosocial function. JAMA. 1963;185(12):914-9. https://doi.org/10.1001/ja ma.1963.03060120024016.

30. Lawton MP, Brody EM. Assessment of older people: self-maintaining and instrumental activities of daily living. Gerontologist. 1969;9(3):179-86. https://doi.org/10.1093/geront/9.3_Part_1.179.

31. Williams DR, Mohammed SA. Discrimination and racial disparities in health: evidence and needed research. J Behav Med. 2009;32(1):20-47. https://doi. org/10.1007/s10865-008-9185-0

32. Legal Affairs. Issues of Social Justice : Scheduled Castes and Scheduled Tribes and Other Backward Classes - An unfinished national Agenda. URL: https://legalaffairs.gov.in/sites/default/files/IX.ISSUESOF\%20SOCIAL\%2 OJUSTICE\%20\%20SCHEDULED\%20CASTES\%20\%20AND\%20SCHEDULED\%2
OTRIBES\%20AND\%200THER\%20BACKWARD\%20CLASSESAN\%2 OUNFINISHED\%20NATION.pdf Accessed 2 Feb 2021

33. Berkman LF, Sekher TV, Capistrant B, Zheng Y. Social networks, family, and care giving among older adults in India. In: Smith JP, Majmundar M, editors. Aging in Asia: findings from new and emerging data initiatives. Washington DC: The National Academic Press; 2012. p. 261-78.

34. Lamont RA, Swift HJ, Abrams D. A review and meta-analysis of age-based stereotype threat: negative stereotypes, not facts, do the damage. Psychol Aging. 2015;30(1):180-93. https://doi.org/10.1037/a0038586.

35. Wyatt SB, Williams DR, Calvin R, Henderson FC, Walker ER, Winters K. Racism and cardiovascular disease in African Americans. Am J Med Sci. 2003;325(6): 315-31. https://doi.org/10.1097/00000441-200306000-00003.

36. Unger JB. Perceived discrimination as a risk factor for use of emerging tobacco products: more similarities than differences across demographic groups and attributions for discrimination. Subst Use Misuse. 2018;53(10): 1638-44. https://doi.org/10.1080/10826084.2017.1421226.

37. Kessler RC, Mickelson KD, Williams DR. The prevalence, distribution, and mental health correlates of perceived discrimination in the United States. J Health Soc Behav. 1999;40(3):208-30. https://doi.org/10.2307/2676349.

38. Ayalon L. Perceived age, gender, and racial/ethnic discrimination in Europe: results from the European social survey. Educ Gerontol. 2014;40(7):499-517. https://doi.org/10.1080/03601277.2013.845490.

39. Peltzer K, Pengpid S. Perceived everyday discrimination among older adults in India: national prevalence and associated factors in 2017-2018. In: Merrick J, editor. Social and health issues among older adults in India. New York: Nova Publishers; 2021

40. Rippon I, Kneale D, de Oliveira C, Demakakos P, Steptoe A. Perceived age discrimination in older adults. Age Ageing. 2014;43(3):379-86. https://doi. org/10.1093/ageing/aft146.

41. Bhan N, Rao KD, Kachwaha S. Health inequalities research in India: a review of trends and themes in the literature since the 1990s. Int J Equity Health. 2016;15(1):166. https://doi.org/10.1186/s12939-016-0457-y.

42. Verma VR, Dash U. Horizontal inequity in self-reported morbidity and untreated morbidity in India: Evidence from National Sample Survey Data. Int J Equity Health. 2021;20(1):49. https://doi.org/10.1186/s12939-020-013760 .

43. Sinha D, Mishra PS, Srivastava S, Kumar P. Socio-economic inequality in the prevalence of violence against older adults - findings from India. BMC Geriatr. 2021;21(1):322. https://doi.org/10.1186/s12877-021-02234-6.

44. Mays VM, Cochran SD, Barnes NW. Race, race-based discrimination, and health outcomes among African Americans. Annu Rev Psychol. 2007:58(1): 201-25. https://doi.org/10.1146/annurev.psych.57.102904.190212.

\section{Publisher's Note}

Springer Nature remains neutral with regard to jurisdictional claims in published maps and institutional affiliations.

Ready to submit your research? Choose BMC and benefit from:

- fast, convenient online submission

- thorough peer review by experienced researchers in your field

- rapid publication on acceptance

- support for research data, including large and complex data types

- gold Open Access which fosters wider collaboration and increased citations

- maximum visibility for your research: over $100 \mathrm{M}$ website views per year

At $\mathrm{BMC}$, research is always in progress.

Learn more biomedcentral.com/submissions 